\title{
The Prevalence and Antecedents of Nationalism Conspiracy Theories During Covid-19 in China
}

\author{
Ming $\mathrm{Mu}^{1}$ \\ ${ }^{1}$ College of Foreign Languages and Cultures, Xiamen University, Xiamen, Fujian 361000, China \\ Email: ssfiregunxd@163.com
}

\begin{abstract}
The deadly COVID-19 has been spreading across the globe, causing large-scale deaths, disruptions, recession, and distress. While most governments and citizens have been doing their best to tackle the challenges set by the pandemic, the difficult time also incubated disruptive thoughts, such as pandemic-related conspiracy theories. In China, the pandemic as well as the recently rising sentiment of nationalism caused the prevalence of the so-called nationalism conspiracy theories - the conspiracy theories that mix with nationalistic sentiment and that aim to devalue the other country. The most influential one of this kind is the one that claims the virus was manufactured by the United States and was used as a biological weapon to undermine Chinese economic development. In the current study, with a quantitative design, I intended to investigate the personality and attitudinal antecedents of nationalism conspiracy beliefs, based on evolutionary psychology as well as the political psychology perspective. Via a set of regression analysis, it has been found that one's average score of the Dark Triad Personality (i.e., the general darkness) but not the impression about the target country, which was significant predictors of nationalism beliefs. Theoretical and practical implications were also discussed.
\end{abstract}

Keywords: Covid-19 Dark-Triad Personality Conspiracy beliefs

\section{INTRODUCTION}

As the deadly COVID-19 spreads across the globe, causing more than 200 thousand deaths, conspiracy theories about the coronavirus are also circulating on both online and offline public spaces, causing misunderstandings and stress among a large population. Some of these conspiracy theories are more like a joke, such as the description of the magic effect of a Chinese traditional herbal drink that could prevent and cure the virus without further medical assistance; such a claim induced crazy stock-up of this drink across multiple cities. Some other conspiracy theories, additionally, are even more consequential economically and politically. For example, recent articles reported that $5 \mathrm{G}$ networks and radio waves can amplify COVID-19 related symptoms and even facilitate the transmission of the virus. Such a seemingly ridiculous claim has been widely spread on social media platforms such as Twitter, Facebook, and Instagram, causing panic in civilians and triggering offline violence. No matter how ridiculous these conspiracy theories are conceived to be, they still attract believers and continue to cause distractions, chaos, and disorders to the collective efforts to recover from the pandemic. As such, to disappoint the inventors of these conspiracy theories and prevent these appalling statements from further spreading and damaging, it is of critical importance to understand its psychological antecedents: are certain groups of people particularly susceptible to conspiracy theories? If so, to what extent?

Conspiracy theories are commonly defined as explanatory beliefs about a powerful group of alien actors that cooperate in secret to reach malevolent goals against groups that the believers belong (Bale, 2007; Van Prooijen, 2018). Quite a few conspiracy theories have been circulating on Chinese social networks during the current epidemic. Among these ideas, arguably the one that attracted the most believers and followers was the one that claimed the virus was manufactured by the United States and was used as a biological weapon to undermine Chinese economic development. Though numerous scientific studies have consistently demonstrated that, from its structure, the virus was implausible to be man-made (Anderson et al., 2020), such a conspiracy gained endorsements from a large proportion of the Chinese population, especially before the pandemic finally reaching the United States. Such a conspiracy, mixed with the nationalistic sentiment, is termed as a nationalism conspiracy theory (Cichocka, \& Cislakm 2020), and it differs from other conspiracy theories in its close connection with the nationalistic thoughts. In the current study, I will particularly examine the individual susceptibility to nationalism conspiracy theories, during the current pandemic, and thereby facilitate a more tailored, specified, effective, and prompt effort of intervention. It should be noted that although the current examination is subjective to the Chinese context, nationalism conspiracy theories have appeared in 
numerous countries, such as Poland (Cichocka \& Cislakm, 2020) and the United States.

The current article will be organized as follows. In the second part, I review previous literature that covered individual differences in conspiracy beliefs and propose the hypotheses. In the third part and fourth part, the method of the survey was detailed and the results were reported. The fourth part contains further discussion on the implications, discussions, and limitations of the current study.

\section{LITERATURE REVIEW AND HYPOTHESES}

\subsection{Nationalism conspiracy theories}

Conspiracy theories are commonly defined as explanatory beliefs about a powerful group of alien actors that cooperate in secret to reach malevolent goals against groups that the believers belong to (Bale, 2007; Van Prooijen, 2018). Theories have been developed from an evolutionary perspective to explain the origin of conspiracy thinking and beliefs. The Adaptive Hypothesis asserts that conspiracy theories have served protection purposes in ancient hunter-gatherer societies against intergroup conflict - they signalized the potential risks associated with the opposing group (Van Prooijen \& Van Vugt, 2018). In other words, conspiracy theories originate from an evolutionary urgency to the detection of potential enemies in order to take proactive measures. As a special form of conspiracy theories, in addition to the essence of conspiracy theories that concern secret goals and behaviors, nationalism conspiracy theories particularly involve a sense of nationalism that associates the foreign nations as the actor of secret behaviors.

Nationalism refers to the presumed sense of superiority of one's nation to another. A closely related yet distinct concept is patriotism, the degree to which one individual takes pride in the nationality (Schatz, 1999). The most striking difference between the two is that nationalism, but not patriotism, relates to hostility towards other nations (Kosterman, \& Feshbach, 1989). Recent interpretations of system justification theory (Jost et al., 2004) have posited that national attachment may be a means of attaining the system-justifying goal to defend existing social systems against criticism. In this way, in-group members are expected to generate negative stereotypes of the out-group and incur comparative social judgment that brings tangible advantages to the in-group (Tajfel, 1975). To fulfill such a goal of creating negative stereotypes, many utilized nationalism conspiracy theories as a handy tool, as they depict a vivid story about the evil foreigners and they are relatively difficult to falsify.

Such nationalism conspiracy theories, linked closely to general nationalistic sentiment, thrive in times of disruptive social settings that easily create a void of safety and sense of control that demands justification and protection of the in-group. Group relationships between countries are conceived as more strained particularly in the time of natural or man-made disasters and social distress, such as during the COVID-19 pandemic. It is not surprising that such conspiracy theories have been prevalent across the globe, especially among the areas that have been greatly affected by the virus. In China, a conspiracy theory was circulating on the internet that accused the United States of deliberately manufacturing the virus and facilitating its spread in China. In some European countries, conspiracy beliefs are rising that attack the Chinese government for not actively controlling the pandemic and allowing it to spread out of the country. Who generally has a greater tendency to take these ridiculous theories seriously and is more inclined to hold nationalism conspiracy beliefs? Below we briefly summarized its potential personality determinants.

\subsection{Conspiracy beliefs, the dark triad of personality, and the attitude to out-groups}

Bouchekir and Boukala [19], He et al. [20], Komuravelli et al. [21], Feng et al. [22] and [23] are the automated assumption generation methods for solving the AG-SMC problem. They can be divided into the following three kinds further.

\subsubsection{Hypothesis 1}

Psychological studies have consistently illustrated the most influential predictors of conspiracy beliefs to be the dark triad of personalities, namely narcissism, Machiavellianism, and psychopath (Paulhus, \& Williams, 2002; Jones, \& Paulhus, 2014). To varying degrees, all three entail a socially malevolent character with behavior tendencies toward self-promotion, emotional coldness, duplicity, and aggressiveness. Machiavellianism highlights a cold and manipulative behavior fashion that puts personal interest as a precondition for action; narcissism highlights grandiosity, entitlement, dominance, and superiority, and its high level of self-identification and self-awareness allows it to be connected with nationalism; psychopathy takes high impulsivity and thrill-seeking along with low empathy and anxiety as its central features (Hare, 1985; Lilienfeld \& Andrews, 1996)

Narcissism comprises two primary sub-categories: Grandiose narcissism, indicating a grandiose sense of self and superiority; and vulnerable narcissism, indicating a vulnerable sense of self, insecurity, and negativity (Jones, $\&$ Paulhus, 2014). Both types are inclined to rely on outside cues to validate the self and the national image. Empirically, Cichocka et al., (2016) found that collective narcissism predicted belief in out-group conspiracies. Nationalism conspiracy theories provide a chance for narcissists to justify their group identities and claim morally higher grounds which is a strong boost to their ego. Therefore, I proposed the Hypothesis 1A 
Hypothesis 1A: people with a higher level of narcissism on average have a higher level of nationalism conspiracy belief.

People with Machiavellianism are cynical and manipulative, having faith in conspiracy theories as a way of defense (Muris et al., 2017). The willingness to " compile " establishes a relationship between Machiavellianism and conspiracy beliefs. Critically, Individuals with a higher level of Machiavellianism would probably take the secret actions if they were in the position and were in charge of the situation (March \& Springer, 2019). Because of such a strong agreement between their thoughts and the conspiracies, one with a higher level of Machiavellianism is believed to exert a higher degree of conspiracy beliefs. This conjecture was expounded in Hypothesis 1B

Hypothesis 1B: people with a higher level of Machiavellianism on average have a higher level of nationalism conspiracy beliefs.

Research has shown that belief in a conspiracy theory is significantly associated with stronger paranormal beliefs and can be predicted by lower Agreeableness (Galliford, \& Furnham, 2017). This provides a practical link to connect trait psychopath and conspiracy beliefs: a higher level of conspiracy beliefs is closely related to a lower degree of agreeableness as well as a higher level of anxiety, both are important indicators of a higher level of trait psychopath. As such, Hypothesis 1C was put forward as follows.

Hypothesis 1C: people with a higher level of trait psychopath on average have a higher level of nationalism conspiracy beliefs.

Overall, the dark triad theory offers a fascinating framework for understanding the " dark" side of personalities (Paulhus, 2014). Besides the effects of each of the three dark personalities, the overall darkness - the average score computed from the three personalities - as a composite of the dark-triad taxonomy, is also predicted to be positively related to nationalism conspiracy beliefs. Critically, it offers a detailed outlook that covers a wide range of dark personalities, resulting in a potentially higher statistical power.

Hypothesis 1D: people with a higher level of darkness on average have a higher level of nationalism conspiracy belief.

\subsubsection{Hypothesis $2 \& 3$}

Last, as nationalism conspiracy beliefs enjoy a unique characteristic of accusing other nations of destructive behaviors, the attitudes to the specific outgroup may also play a critical role in forming one' $\mathrm{s}$ conspiracy beliefs. More particularly, if one has long taken the specific outgroup as enemies, a group of people intentionally causing damage, the nationalism conspiracy theories is then just another proof of the hateful nature of the outgroups. Theoretically, the two cores of nationalism conspiracy beliefs - an antagonistic attitude to the outgroup and the general tendency of conspiracy beliefs - contribute to nationalism conspiracy beliefs in both direct and interacting ways. Therefore, Hypotheses 2 and 3 were proposed

Hypothesis 2: one' s impression of the specific outgroup is negatively related to nationalism conspiracy beliefs.

Hypothesis 3: one' s impression of the specific outgroup buffered the positive effects of dark-triad personalities and nationalism conspiracy beliefs.

\section{DATA ANALYSIS}

In the current study, a total of 157 participants were recruited from online social platforms QQ and WeChat. The average age of the participants was 24.68 ( $\mathrm{SD}=9.77$ ), with the maximal age at 55 and the minimum at 17 . The responses were free of missing entries.

The dark personality traits (Narcissism, Machiavellianism, and Psychopathy) are measured by the Short Dark Triad (SD3) (Jones, \& Paulhus, 2013). Participants were directed to evaluate to what extent they would describe themselves with the statements corresponding with different aspects of a particular dark personality. The scales are soundly reliable with Cronbach' $\mathrm{s}$ Alpha equaling .81 for the three dimensions of dark personality scale.

General impression about the States, a measurement with regard to participants' perception about the inter-group threat, was measured by 3 items - an example item was

"In general, I have a positive impression of the United States” . Participants were instructed to report on a 7 point Likert scale. The average score was $3.44 \quad(\mathrm{SD}=1.15)$, indicated a generally negative impression towards the states. Furthermore, when asked to rate the extent of tension and opposition between China and the States, 74\% of respondents selected between easily detectable (4) up to obvious (7). Age, education, and gender were also measured and included as control variables.

A sequential regression analysis strategy was applied to test the hypotheses. Three models were built with increasing complexities for adding predictors accumulatively. More specifically, Model 1, the baseline model, only included all control variables. The main effects were added in Model 2 along with the control variables while the interaction terms were only included once in Model 3. In addition, we conducted two versions of analyses; in the first version, the dark trait was treated as a single dependent variable while in the second version, the three subscales (i.e. narcissism, psychopathy, and Machiavellianism) were treated separately. 
Table 1: Means, standard deviations, and correlations with confidence intervals

\begin{tabular}{|c|c|c|c|c|c|}
\hline \multicolumn{2}{|l|}{ Variable } & $\mathbf{M}$ & SD & 1 & 2 \\
\hline \multicolumn{2}{|l|}{1 Age } & 24.68 & 9.774 & 1 & $-0.355 *$ \\
\hline \multicolumn{2}{|l|}{2 Education } & 4.86 & 0.525 & $-0.355 * *$ & 1 \\
\hline \multicolumn{2}{|l|}{3 Impression } & 3.4374 & 1.15276 & $-0.229 * *$ & $0.25 * *$ \\
\hline \multicolumn{2}{|c|}{4 Machiavellianism } & 4.0679 & 1.13546 & $-0.179 *$ & 0.131 \\
\hline \multicolumn{2}{|l|}{5 Narcissism } & 3.3178 & 0.82166 & -0.122 & 0.091 \\
\hline \multicolumn{2}{|l|}{6 Psychopathy } & 3.0127 & 0.94574 & -0.61 & 0.141 \\
\hline \multicolumn{2}{|l|}{7 Aggregation } & 3.4661 & 0.74228 & $-0.162 *$ & $0.16 *$ \\
\hline \multicolumn{2}{|c|}{8 Belief in Conspiracy Theory } & 6.4586 & 1.61718 & $0.207 * *$ & $-0.218 *$ \\
\hline 3 & 4 & 5 & 6 & 7 & 8 \\
\hline$-0.229 * *$ & $-0.179 *$ & -0.122 & -0.061 & $-0.162 *$ & $0.207 * *$ \\
\hline $0.25 * *$ & 0.131 & 0.091 & 0.141 & $0.16 *$ & $-0.218 * *$ \\
\hline 1 & -0.013 & 0.069 & 0.019 & 0.027 & -0.132 \\
\hline-0.013 & 1 & $0.364 * *$ & $0.423 * *$ & $0.824 * *$ & 0.127 \\
\hline 0.069 & $0.364 * *$ & 1 & $0.330 * *$ & $0.695 * *$ & 0.133 \\
\hline 0.019 & $0.423 * *$ & $0.33 * *$ & 1 & $0.762 * *$ & 0.025 \\
\hline 0.027 & $0.824 * *$ & $0.695 * *$ & $0.762 * *$ & 1 & 0.124 \\
\hline-0.132 & 0.127 & 0.133 & 0.025 & 0.124 & 1 \\
\hline
\end{tabular}

The means, standard deviations of variables as well as their correlations are reported in Table 1 . The results do show tendencies that coincide with the hypotheses, though the effects are not significant at the population level. First, trait narcissism, psychopathy, and Machiavellianism are positively correlated with nationalism conspiracy beliefs; Impression about the States was negatively related to nationalism conspiracy beliefs. Other outcomes to be noted are that trait Machiavellianism is highly correlated with narcissism and psychopathy, indicating a strong internal viscous in the dark-triad of personality, also offering important support for treating the dark trait as a single and general factor.

Table 2: Regression results using the general darkness as the single dependent variable

\begin{tabular}{lllll}
\hline & Predictor & b & R2 & R2 \\
Difference
\end{tabular}


Gender

0.05

Education

$-0.51$

Model 2

(Intercept)

1.97

0.102

0.03

Age

0.03

Gender

$-0.54$

Education

0.39*

Darkness

$-0.08$

Model 3

$$
\text { (Intercept) }
$$

1.84

0.113

0.011

Age

0.03

Gender

0.04

Education

$-0.51$

Darkness

0.37*

Impression

$-0.06$

Darkness * Impression

Note. $b$ represents unstandardized regression weights

$*$ indicates $\mathbf{p}<.05$. $* *$ indicates $\mathbf{p}<.01$.

Table 3: Regression results using the three dark traits as dependent variables

\begin{tabular}{lllll}
\hline & Predictor & b & fit & Difference \\
\hline Model 1 & (Intercept) & 1.84 & 0.067 & 0.067 \\
& Age & 0.03 & & \\
Gender & 0.05 & -0.51 &
\end{tabular}


Model 2

(Intercept)

1.77

$\mathbf{0 . 0 3}$

Age

$\mathbf{0 . 0 3}$

Gender

$-0.51$

Education

0.21

Machiavellianism

Narcissism

$-0.08$

Psychopathy

$-\mathbf{0 . 0 8}$

Impression

1.64

0.128

$0.012 * *$

$\begin{array}{ll}\text { Age } & \mathbf{0 . 0 3} \\ \text { Gender } & \mathbf{0 . 0 4} \\ \text { Education } & -\mathbf{0 . 4 8} \\ \text { Machiavellianism } & \mathbf{0 . 2 3} \\ \text { Narcissism } & 0.24 \\ \text { Psychopathy } & -\mathbf{0 . 1 0} \\ \text { Impression } & -\mathbf{0 . 0 6} \\ \text { Interaction } & \mathbf{0 . 0 7}\end{array}$

\section{Note. b represents unstandardized regression weights}

\section{$*$ indicates $\mathbf{p}<.05$. $* *$ indicates $\mathbf{p}<.01$.}

Subsequently, sequential regression analyses were conducted to test the hypotheses. Table 2 and Table 3 report the results of the regression analysis with respectively the aggregate scores - thus indicate the general darkness - and all of the three sub-dimensions of the Dark Triad as predictors. From Table 2, we can conclude that the average level of darkness was correlated significantly and positively with Belief in Nationalism Conspiracy Theory $(b=0.39, p<.05$; Model 2; $b=0.37, p$ $<.05$; Model 3). However, both the impression towards the States ( $b=-.06$, n.s.; Model 3), as well as the interaction between the general darkness and the impression $(b=.21$, n.s.; Model 3), were not related to the degree of conspiracy beliefs in the population level. Subsequently, we intended to test whether this correlation similarly exists between the nationalism conspiracy beliefs and the three sub- dimensions of the dark triad personality, namely trait Machiavellianism, narcissism, and Psychopathy and Belief. The results shown in Table 3, although not significant, do show tendencies corresponding with the hypotheses that the dark triad personality traits and impression about the States are both important predictors of nationalism conspiracy beliefs. More specifically, trait Machiavellianism ( $b=.23$, n.s.; Model 3) and narcissism $(b=.37$, n.s; Model 3 ) is found to be positively related to nationalism conspiracy beliefs only in the sample but these conclusions could not be generated to the population level. However, in agreement with Table 2, the analysis did not support our hypothesis that the impression about the States negatively related to conspiracy beliefs nor did it endorse its moderating effect on the relationship between dark personalities and nationalism conspiracy beliefs 
Note that education negatively correlated with nationalism conspiracy beliefs ( $b=-0.51$, Model 1,$2 ; b=-0.48$, model 3 ). A possible explanation of this result is that analytical thinking and reasoning - factors that are consistently found to be positively related to education level - reduces impulsivity and insufficient logic that directs individuals to conspiracy thinking.(Gábor Orosz, Péter Krekó, 2016; Viren Swami, Martin Voracek, 2014)

Discussion

The objective of the current study was to assess the degree to which the Dark Triad Personalities (Machiavellianism, narcissism, and psychopathy) can predict nationalism conspiracy beliefs - a specific type of conspiracies about a rival or hostile country, in the context of the COVID-19 pandemic.

Although in agreement with our hypotheses, the general darkness was indeed positively related to conspiracy beliefs, the three dimensions were not connected to conspiracy beliefs at the population level. The first possible explanation of such a pattern is that the current research concerns specifically the Covid-19 pandemic, and people - even those score low in the three dimensions of dark triad personality - may have a stronger general tendency to hold conspiracy beliefs, in order to reduce the general sense of uncertainties. Second, the material of the conspiracy theory in the current research was unique in that it has not only been speculated online but also appeared in mainstream media. As such, comparing to other conspiracy theories, they may be endorsed by a larger proportion of the population and the personal factors - characterized by, for example, the dark personalities may thus play a marginal role. Last, the sample of 157 participants may be too small to distinguish a clear pattern, since research which produces tangible results usually recruits over a thousand participants.

\section{CONCLUSION}

Nationalism conspiracy theory is defined as the conspiracy theory that targets a rival out-group and stirs hostility among the believers to attain certain goals. Therefore, it is a two-dimensional concept that comprises nationalism and conspiracy beliefs. As conservative thoughts are on the rise internationally, this specific type of conspiracy theory may spread more extensively with the help of the Internet and deserves more attention now that its influence is more tangible and climbs to a higher order of magnitude.

Recent research has pointed out that nationalism is negatively associated with governmental respect for several human rights since nationalist politicians prioritize national interest and unity over humane concerns (Yazici, 2019). The jeopardized human rights are specified by latter research as the "six 'empowerment' rights" (i.e. the freedoms of assembly and association, electoral selfdetermination, speech, foreign movement, religion, and worker's rights), which also proposes that whether or not a chief executive is a faithful nationalist influence states decisions concerning human rights. Therefore, nationalism's influence on human rights is greater than presumed before, which can be seen clearly in the current situation of epidemic prevention in the States under the leadership of Trump's administration. From this perspective, the situation calls for controlling measures for nationalism conspiracy beliefs.

On the other hand, conspiracy theories emerging as a result of victimizing events, such as the Covid-19 pandemic, may lead to greater social distance between conspiracy believers and non-believers, between believers and skeptics. The disastrous consequence may be an even wide gap between different social groups and a breach of social cohesion (Michal et al., 2019).

It has also been proposed that exposure to conspiracy theories twists citizens' decisions in a way that may harm their own interests. For example, when briefed about antivaccine conspiracies, parents demonstrate lower intentions to vaccinate their children (Jolley \& Douglas, 2014). Besides, conspiracy theories - such as the one that claimed global warming is fabricated - damage public support for crucial policies and thus citizens from cutting back on their carbon footprints and adopt a greener lifestyle (Jolley \& Douglas, 2014). On an individual level, conspiracy theories are correlated with a jeopardized interpersonal functioning (Harambam 2015), evoking paranoia about fear of social exclusion (Imhoff \& Lamberty, 2018) and other negative emotions that act as barriers for normal socialization. To sum up, conspiracy theories have extensive and profound influence from micro to macro levels of societal issues. Thus it is reasonable to postulate that nationalism conspiracy theories may incur more serious societal disruptions since it attracts a larger population and can easily influence people's perceptions of social, political, and cultural policies.

Future research can build on the present study and explore further the interplay between nationalism and personality traits possibly beyond the dark triad, through experimental tests and a longitudinal design. Future studies are encouraged to distinguish connections between conspiracy theories and other modern complexes beyond nationalism with regard to different cultural, political, and social contexts and under what circumstances the interplay of conspiracy theories and the newly discovered elements are harmful, moderately disturbing, harmless or reversely, beneficial.

\section{REFERENCES}

[1] Andersen, K. G., Rambaut, A., Lipkin, W. I., Holmes, E. C., \& Garry, R. F. (2020). The proximal origin of SARS-CoV-2. Nature medicine, 26(4), 450-452.

[2] Bale, J. M. (2007). Political paranoia v. political realism: On distinguishing between bogus conspiracy theories and genuine conspiratorial politics. Patterns of Prejudice, 41(1), 45-60. 
[3] Bilewicz, M., Witkowska, M., Pantazi, M., Gkinopoulos, T., \& Klein, O. (2019). Traumatic Rift: How Conspiracy Beliefs Undermine

[4] Cohesion After Societal Trauma. European journal of psychology, 15(1), 82-93. https://doi.org/10.5964/ejop.v15i1.1699

[5] Cichocka, A., \& Cislak, A. (2020). Nationalism as collective narcissism. Current Opinion in Behavioral Sciences, 34, 69-74.

[6] Hare, R. D. (1985). Comparison of procedures for the assessment of psychopathy. Journal of consulting and clinical psychology, 53(1), 7

[7] Jost, J. T., Banaji, M. R., \& Nosek, B. A. (2004). A decade of system justification theory: Accumulated evidence of conscious and unconscious bolstering of the status quo. Political Psychology, 25(6), 881-919.

[8] Jones, D. N., \& Paulhus, D. L. (2014). Introducing the short dark triad (SD3) a brief measure of dark personality traits. Assessment, 21(1), 28-41.

[9] Jolley D, Douglas KM. (2014). The social consequences of conspiracism: Exposure to conspiracy theories decreases intentions to engage in politics and to reduce one's carbon footprint. British Journal of Psychology. 105(1):35-56. doi:10.1111/bjop.12018

[10] Harambam J, Aupers S. (2015). Contesting epistemic authority: Conspiracy theories on the boundaries of science. Public Understanding of Science. 24(4):466-480. doi:10.1177/0963662514559891

[11] Imhoff, R. and Lamberty, P. (2018). How paranoid are conspiracy believers? Toward a more fine-grained understanding of the connect and disconnect between paranoia and belief in conspiracy theories. European Journal of Social Psychology 48: 909-926. doi:10.1002/ejsp.2494

[12] Galliford, N., \& Furnham, A. (2017). Individual difference factors and beliefs in medical and political conspiracy theories. Scandinavian journal of psychology. 58(5), 422-428.

[13] Lilienfeld, S. O., \& Andrews, B. P. (1996). Development and preliminary validation of a self-report measure of psychopathic personality traits in noncriminal population. Journal of personality assessment, 66(3), 488524.

[14] March, E., \& Springer, J. (2019). Belief in conspiracy theories: The predictive role of schizotypy, Machiavellianism, and primary psychopathy. PloS one, 14(12)
[15] Muris, P., Merckelbach, H., Otgaar, H., \& Meijer, E. (2017). The malevolent side of human nature: A metaanalysis and critical review of the literature on the dark triad (narcissism, Machiavellianism, and psychopathy). Perspectives on Psychological Science, 12(2), 183-204.

[16] Paulhus, D. L., \& Williams, K. M. (2002). The dark triad of personality: Narcissism, Machiavellianism, and psychopathy. Journal of research in personality, 36(6), 556-563.

[17] Paulhus, D. L. (2014). Toward a taxonomy of dark personalities. Current Directions in Psychological Science, 23(6), 421-426.

[18] Schatz, R. T., Staub, E., \& Lavine, H. (1999). On the varieties of national attachment: Blind versus constructive patriotism. Political Psychology, 20(1), 151-174.

[19] Turner, J. C. (1975). Social comparison and social identity: Some prospects for intergroup behaviour. European journal of social psychology, 5(1), 134.

[20] van Prooijen, J. W. (2018). The psychology of conspiracy theories. Routledge.

[21] van Prooijen, J. W., \& Van Vugt, M. (2018). Conspiracy theories: Evolved functions and psychological mechanisms. Perspectives on psychological science, 13(6), 770-788.

[22] van Prooijen, J. W., \& Douglas, K. M. (2018). Belief in conspiracy theories: Basic principles of an emerging research domain. European journal of social psychology, 48(7), 897-908.

[23] Yazici E. Nationalism and human rights. (2015). Political Research Quarterly. 72(1):147-61. 10.1177/1065912918781187) 